\section{UTILIZAÇÃO DE JOGO DIDÁTICO PARA O ENSINO DE TABELA PERIÓDICA}

Game use of teaching for periodic table of education

Utilización de juego didáctico para la enseñanza de tabla periódica

\section{AUTORES:}

ADRIANA VIEIRA DOS

SANTOS ${ }^{1}$

ORCID 0000-0002-6441-1605

${ }^{1}$ Instituto Federal da

Bahia

$\overline{\text { FELIPE BARBOSA ARAÚJO }^{2}}$

ORCID 0000-0002-5491-9974

2 Instituto Federal da

Bahia o demonstraremos a utilização do jogo QUIMIF para o ensino de tabela periódica. Foram aplicados questionários para verificação de aceitação do jogo entre os estudantes bem como o potencial do jogo no êxito ao ensino. A partir da aplicação do jogo, percebeuse a identificação dos estudantes, uma vez que, foram utilizados objetos do cotidiano destes para ilustrar os conteúdos vistos em sala de aula sobre elementos químicos. $\mathrm{O}$ jogo citado proporcionou momentos de aprendizado, ao mesmo que, configura-se uma alternativa para auxílio a práticas pedagógicas.

Palavras-chave: jogo didático, tabela periódica, ensino

\begin{abstract}
Games can be used as a tool in the teaching of chemistry content. In this article we demonstrate the use of QUIMIF game for the periodic table of education. Questionnaires were applied to the game check acceptance among students as well as the game's potential success in teaching. From the application of the game, we realized the identification of students, since, everyday objects were used to illustrate these visas content in the classroom on chemicals. The game provided cited learning moments, the same that sets up an alternative to aid the teaching practices.
\end{abstract}

Keywords: didactic game, periodic table, teaching

\section{Resumen}

Los juegos pueden ser utilizados como herramienta en la enseñanza de los contenidos de química. En este artículo demostraremos la utilización del juego QUIMIF para la enseñanza de tabla periódica. Se aplicaron cuestionarios para verificación de aceptación del juego entre los estudiantes así como el potencial del juego en el éxito a la enseñanza. A partir de la aplicación del juego, se percibió la identificación de los estudiantes, una vez que, se utilizaron objetos del cotidiano de éstos para ilustrar los contenidos vistos en el aula sobre elementos químicos. El juego citado proporcionó momentos de aprendizaje, al mismo que, se configura una alternativa para ayudar a prácticas pedagógicas.

Palabras clave: juego didáctico, tabla periódica, enseñanza

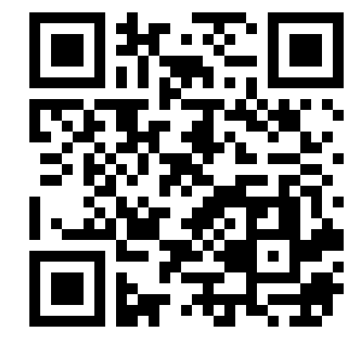

Para citar este artigo:

SANTOS, A. V.; ARAÚJO, F. B. Utilização de jogo didático para o ensino de tabela periódica.

Revista

Eletrônica Ludus

Scientiae, Foz do Iguaçu, v. 01, n. 02, p. 78-89, ago./dez. 2017. 


\section{INTRODUÇÃO}

Os jogos sempre fizeram parte de todas as etapas da vida (HUIZINGA, 2000). Além de servirem como entretenimento podem, também, contribuir na formação do aluno, considerando que o jogo é um tipo de linguagem e a sua capacidade de produzir sentido. Alguns autores destacam os jogos como elementos motivadores e facilitadores do processo de ensino e aprendizagem de conceitos científicos (KISHIMOTO, 1994). Assim, os jogos possuem duas características que juntas são interessantes: a ludicidade e a aprendizagem.

Com a consolidação das tecnologias digitais, a presença dos jogos educativos em sala de aula tem crescido gradativamente. Muitos educadores acreditam que a interferência destes, nesse ambiente, transformam os encontros escolares em menos metódicos e ajudam no desenvolvimento de habilidades e competências, deixando para trás as hierarquias construídas pelo modelo educacional tradicional, assim, proporcionando uma melhor interação entre professores e alunos (WOLFF, 2013).

As tecnologias digitais têm impulsionado transformações importantes na maneira de ensinar e aprender, logo, se pode fazer associações com teorias que ampliam a compreensão sobre como se dá a construção do conhecimento. Piaget, em sua teoria da construção do conhecimento, já apontava que essa construção se dar pela interação entre sujeito e objeto (ARGENTO, 2008). Outras pesquisas vinculadas aos avanços científicos em áreas como a neurocognição, associadas às investigações desenvolvidas pela Psicologia do Desenvolvimento, apontam que crianças e adolescentes da atualidade encontram-se mergulhados em um mundo de tecnologias digitais e virtuais. Essas pesquisas têm orientado educadores a perceberem que a aprendizagem não ocorre simplesmente pela transmissão de informações, mas sim pela construção da interação do sujeito com o meio. Deste modo, o indivíduo abandona o estágio de passivo, receptor de informações, e passa para o estágio de ativo, que interage, constrói, participa, experimenta e se relaciona com o conhecimento (FROSI; SCHLEMMER, 2010).

Estudos e pesquisas, em particular, no ensino de química, demonstram que os alunos, muitas vezes, não conseguem aprender e não são capazes de associar o conteúdo estudado com seu cotidiano, tornando-se desinteressados pelo tema. Isto indica que este ensino está sendo feito de forma descontextualizada e não interdisciplinar (NUNES; ADORNI, 2010).

SOARES (2016) estudou o cenário de desenvolvimento de jogos na área da química no Brasil, e segundo o autor nos últimos anos, mais precisamente, a partir dos anos 2000, ocorreu um aumento gradual do uso de atividades lúdicas e jogos no ensino da química, logo, contribuindo para o aprofundamento teórico sobre a temática. Para o autor o crescimento da inserção das ferramentas lúdicas no âmbito da química, também, pode ser atribuído a funcionalidade dessas propostas quando bem inseridas, planejadas, teorizadas e aplicadas. Entretanto, de acordo com Soares (2016), muitas das discussões teóricas levantadas sobre a problemática da inserção dos jogos no ensino da química ainda enfrentam o desafio do uso ineficiente das teorias envolvendo jogos, assim como, também, a ausência do diálogo entre os jogos e as teorias de ensino aprendizagem.

A tabela periódica é usada como uma ferramenta de linguagem específica e a partir dela é possível realizar diversas observações, no entanto, foi por muito tempo usada para que o aluno decorasse nomes e símbolos químicos, sem realizar a reflexão do uso desses elementos no cotidiano. Portanto, os jogos didáticos, sobre tabela periódica, constituem-se em um dos parâmetros de compreensão da simbologia química dos elementos, localização de cada um deles por grupos ou famílias em que estão organizadas assim como suas aplicações no cotidiano.

Atualmente existem diversos jogos didáticos para o ensino da química que abordam com temática principal a tabela periódica e suas propriedades. Godoi, Oliveira e Codognoto (2010), 
desenvolveram e aplicaram um jogo didático, que aborda a Tabela Periódica e suas devidas propriedades e aplicabilidades periódicas, para alunos de Ensino fundamental e médio. O jogo Super Trunfo da Tabela Periódica foi desenvolvido baseado no jogo de cartas e é comercialmente chamado de Super Trunfo. Esse jogo permitiu aos alunos tratarem o tema de maneira dinâmica, realizando comparações entre os elementos químicos e ajudando também a entender o posicionamento de cada elemento químico na Tabela Periódica. Segundo os autores da proposta, os alunos se mostraram mais estimulados pelas atividades, favorecendo a aprendizagem. A atividade mostrou-se uma boa alternativa, visto que os alunos cobraram os jogos em outras aulas e se interessaram em confeccionar as cartas para que pudessem jogar fora da sala de aula.

Cardoso (2014) desenvolveu o jogo "As aventuras no mundo da tabela periódica", nessa ferramenta didática o jogador se encontrará no "mundo da tabela periódica", onde poderá interagir com elementos químicos visualizando suas informações ou coletando amostras, que poderão ser utilizadas mais adiante. A interação com elementos é simples, bastando posicionar o avatar sobre o elemento escolhido na tabela e pressionar a tecla de ação desejada. A relevância desse trabalho está na busca de soluções para diminuir as dificuldades apresentadas na aprendizagem de conteúdos da Química, ocorrendo a necessidade de se investir na integração das tecnologias digitais ao ensino de forma que se promova um processo de aprendizagem mais significativo e integrado ao dia a dia. Ambas ferramentas, citadas acima, trouxeram contribuições importantes no ensino da química, em principal na temática da tabela periódica, contribuindo para que novas ferramentas sejam desenvolvidas.

O objetivo deste artigo é apresentar uma proposta em formato de jogo digital e verificar os conhecimentos adquiridos por alunos do primeiro ano do ensino médio recorrendo a estratégias com a utilização do jogo. Dentre essas estratégias, se considerou a memorização relevante, como um ato mecânico e repetitivo, para adquirir a compreensão e aprendizagem. $\mathrm{O}$ jogo digital didático intitulado "QUIMIF o Caçador de Elementos Químicos" tem como objetivo apresentar e ensinar os elementos químicos componentes da tabela periódica e suas aplicabilidades no dia a dia. São diversas as habilidades desenvolvidas com o uso de jogos, tais como atenção, disciplina, autocontrole, respeito a regras, entre outras.

\section{METODOLOGIA}

"QUIMIF - O caçador de elementos químicos" é um jogo digital didático que foi desenvolvido no Instituto Federal de Educação, Ciência e Tecnologia da Bahia, com o objetivo de contribuir com a aprendizagem dos alunos sobre os elementos e grupos da tabela periódica, e suas aplicabilidades no cotidiano de forma agradável.

O QUIMIF foi produzido no Construct 2 e teve seu processo de elaboração dividido em três etapas: construção do personagem e do design-gráfico do jogo, construção das regras e instruções, e seleção das aplicações dos elementos. O jogo tem como participante um único jogador e pode ser aplicado em escolas com alunos, a partir da 8o série do ensino fundamental, que tenham estudado ou estejam estudando o conteúdo da tabela periódica.

A Figura 1 apresenta a tela inicial do jogo que contém o botão "Jogar", que inicia o jogo, e o botão "Instrução" que apresenta o funcionamento, objetivo do jogo e as teclas que devem ser utilizadas para movimentar o personagem. Como é apresentada na Figura 2, a ferramenta didática contém 9 missões referentes a todos os grupos ou famílias representativas da tabela periódica que foram confeccionadas em nove modelos distintos, baseadas em jogos já existentes, cada uma com um grau de dificuldade diferentes, divididos em: fácil, médio e difícil. 


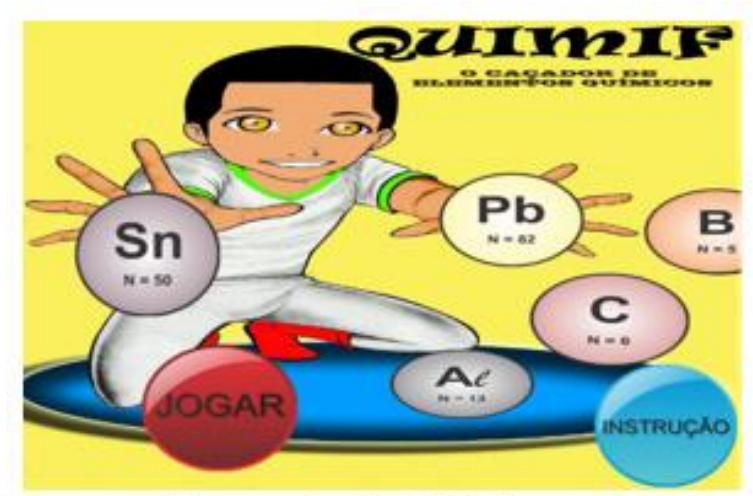

Figura 1: Capa inicial do jogo. Fonte: Elaborada pelos autores.

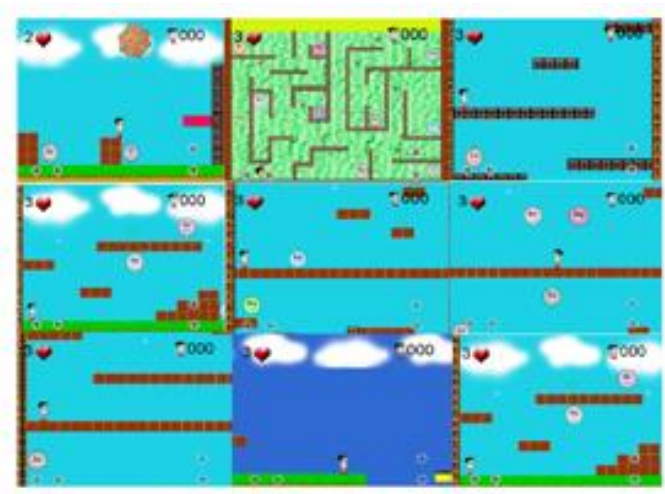

Figura 2: Missões do Jogo. Fonte: Elaborada pelos alunos.

No QUIMIF cada missão possui cinco ou seis elementos, a depender da quantidade de elementos presentes no grupo da tabela que está sendo abordado na missão, referentes ao grupo apresentado, cinco elementos errados de outro grupo e um saldo de três vidas. Ao coletar os elementos corretos, o jogador acumula cem pontos e é apresentada a relação do elemento com o cotidiano, porém, caso um elemento errado seja coletado é subtraída uma vida do jogador, e quando o saldo de vidas é igual a zero a missão na qual se encontra o jogador é reiniciada. $\mathrm{O}$ jogador só consegue concluir a missão, em que está inserido, quando alcança quinhentos ou seiscentos pontos, a depender do grupo da tabela que está sendo abordado.

É importante salientar que o jogador interage com o jogo por meio de um personagem que tem como objetivo coletar os elementos corretos e realizar as missões. Além disso, no decorrer do jogo são apresentados inimigos baseados nos modelos atômicos e a finalidade deles é guardar os elementos e impedir o personagem na realização das missões.

Alguns detalhes a respeito da ferramenta podem ser observados em um vídeo desenvolvido pelo grupo de jogos do IFBA campus Santo Amaro disponível no Youtube (<https://www.youtube.com/watch?v=iHzvwPWEO-Y>).

Este trabalho foi aplicado no Instituto Federal de Educação, Ciência e Tecnologia da Bahia, participando 96 alunos do 1o ano do Ensino Médio. Para a aplicação da proposta, uma sequência de atividades foi elaborada, visando à consolidação de conteúdos sobre Tabela Periódica, após os alunos terem contato com esse conteúdo por meio de uma aula teórica tradicional ministrada pelas professoras de Química da instituição.

As turmas que participaram da proposta foram divididas em dois grupos, turmas controle e turmas teste. As turmas pertencentes ao grupo de controle não jogaram o jogo e responderam os dois questionários, pré e pós-teste, e as turmas teste, também, responderam os dois questionários, porém, jogaram o jogo. Todos os dados apresentados foram devidamente autorizados pelos entrevistados. A divisão das turmas pode ser observada na Tabela 1.

Tabela 1: Divisão e classificação das turmas.

\begin{tabular}{|c|c|}
\hline \multicolumn{2}{|c|}{ Divisão das turmas } \\
\hline Classificação das Turmas & Quantidade de entrevistados \\
\hline Turma Teste 1 & 23 alunos \\
\hline $1^{\circ}$ Ano de Tecnologia da Informação Turma - A & 27 alunos \\
\hline Turma Controle 1 & \\
\hline o Ano de Tecnologia da Informação Turma-B & \\
\hline
\end{tabular}




\begin{tabular}{|c|c|}
\hline Turma Controle 2 & 23 alunos \\
\hline Turma Teste 2 & 23 alunos \\
\hline
\end{tabular}

A sequência de atividades seguiu as seguintes etapas: (i) aplicação de questionário préteste com questões objetivas sobre conhecimentos específicos de química e uma questão subjetiva sobre as dificuldades dos alunos na disciplina Química; (ii) explanação da proposta de trabalho ; (iii) uso do jogo digital QUIMIF sobre o conteúdo tabela periódica; (iv) aplicação de questionário pós-teste com questões objetivas de conhecimentos específicos da tabela periódica e uma questão subjetiva sobre como o jogo pode ter auxiliado a superar as dificuldades no conteúdo de Química

Os dados foram coletados a partir de observações e registros durante o desenvolvimento das atividades e aplicação de questionários pré-teste e pós-teste. Os questionários visaram sondar os conhecimentos dos alunos a respeito do assunto tabela periódica, sendo o pré-teste constituído das seguintes questões: "1-Qual elemento da tabela periódica está presente no sal de cozinha?”,"2- Em qual grupo da tabela periódica está presente o oxigênio?”, "3- Cite qual desses elementos não pertence à família dos metais alcalinos:" "4Quais elementos compõem o grupo dos metais alcalino-terrosos?”, "5- Qual desses elementos pertence à família dos gases nobres?", “6- Qual elemento é encontrado na ponta do lápis?" e "7- Cite quais são suas dificuldades em Química:”. Já o pós-teste foi constituído pelas seguintes questões: "1-A que família pertence o Bromo?”,"2- Qual elemento da família 1A é utilizado como fertilizante?” , "3-Quais elementos pertencem a família dos calcogênios?” , “4Qual dos elementos abaixo pertence à família dos gases nobres?" , "5- O silício é utilizado na fabricação de vidro. A que família ele pertence?" e "6- Você possui alguma dificuldade em química com relação ao assunto tabela periódica? Se sim, qual? O jogo "7-QUIMIF o caçador de elementos químico" te ajudou a superar essa dificuldade?".

\section{RESULTADOS}

Com a finalidade de comparar a ferramenta didática desenvolvida nesse trabalho com outras elaboradas por outros autores, realizamos uma busca superficial no "Google Acadêmico" e como resultado encontramos mais de doze mil publicações utilizando as palavras-chave: jogo e tabela periódica. A partir disso, fizemos a seleção dos jogos descritos na Tabela 2 para realizar uma comparação com o jogo digital QUIMIF.

Tabela 2: Comparação do QUIMIF com outras propostas.

\begin{tabular}{|c|l|}
\hline NOMES DE OUTROS JOGOS & \multicolumn{1}{|c|}{ COMPARAÇ̃̃O COM O QUIMIF } \\
\hline $\begin{array}{c}\text { Super Trunfo da Tabela Periódica } \\
\text { (GODOI; OLIVEIRA; CODOGNOTO, 2010). }\end{array}$ & $\begin{array}{l}\text { Presenç do personagem, favorecendo a } \\
\text { identidade do usuário e por ser uma ferramenta } \\
\text { digital. }\end{array}$ \\
\hline $\begin{array}{c}\text { Assim como o QUIMIF, esse é uma proposta } \\
\text { As aventuras no mundo da tabela }\end{array}$ & $\begin{array}{l}\text { de jogo digital que contém um personagem em busca } \\
\text { de elementos e informações sobre a tabela periódica. } \\
\text { No entanto, o QUIMIF apresenta os elementos da } \\
\text { tabela periódica de forma dinâmica e com o auxílio } \\
\text { de áudio para estabelecer a relação dos elementos } \\
\text { com o cotidiano. }\end{array}$ \\
\hline
\end{tabular}


Tabela periódica animada (OLIVEIRA; SILVA; FERREIRA, 2010).
Jogo de quebra-cabeça analógico que apresenta a tabela periódica de maneira lúdica. Cada peça do quebra-cabeça contém o número atômico, o símbolo, nome, distribuição eletrônica e massa atômica dos elementos químicos. Diferente do QUIMIF, essa proposta não possui regras definidas em relação a número de participantes e sequência de jogadores.

Fonte: Dados da pesquisa.

Analisando e comparando com o QUIMIF, percebemos que o grande diferencial da proposta está na forma dinâmica e animada, que conta com o auxílio de figuras e áudios. Além disso, o QUIMIF aproxima a tabela periódica do cotidiano dos jogadores, mesmo com o estímulo da memorização, enquanto as demais propostas apenas apresentam a tabela periódica e suas propriedades.

Participaram do estudo 58 meninas e 38 meninos, com porcentagens, respectivamente, de $60 \%$ e $40 \%$ como mostra a Figura 3, num total de 96 entrevistados com idades entre quinze e dezenove anos, como é mostrado na Figura 4. Analisando as porcentagens da faixa etária dos entrevistados pode-se perceber que a maioria dos entrevistados, 49\%, possuem 16 anos.

\section{Divisão dos Entrevistados}

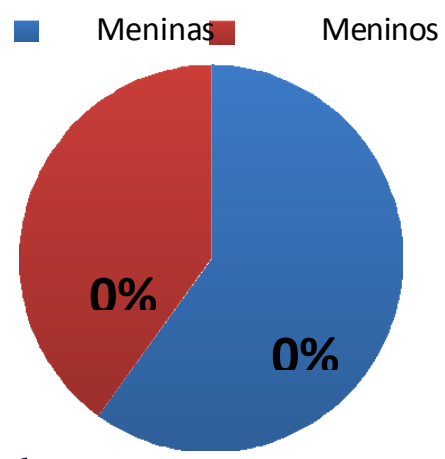

Figura 3: Divisão dos entrevistados entre meninos e meninas.

\section{Idade dos Entrevistados}

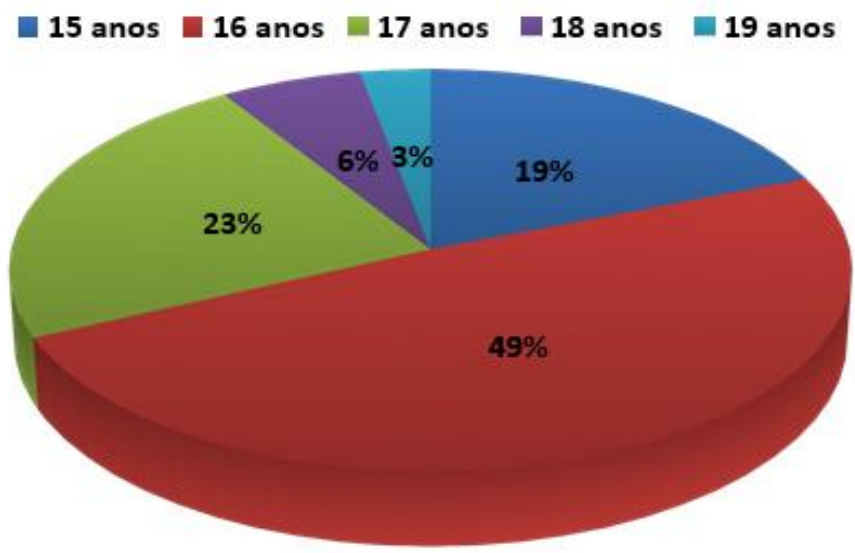

Figura 4: Porcentagem da faixa etária dos entrevistados. 
As médias de acertos das turmas nas questões dos questionários de pré e pós-testes estão representados na Figura 6. Trabalhando com os dados de acertos de cada turma notou-se que as turmas testes, que jogaram o jogo, apresentaram desempenhos superiores, em comparação ao pré-teste, e progressivos no pós-teste.

\section{Médias de Acertos das Turmas}

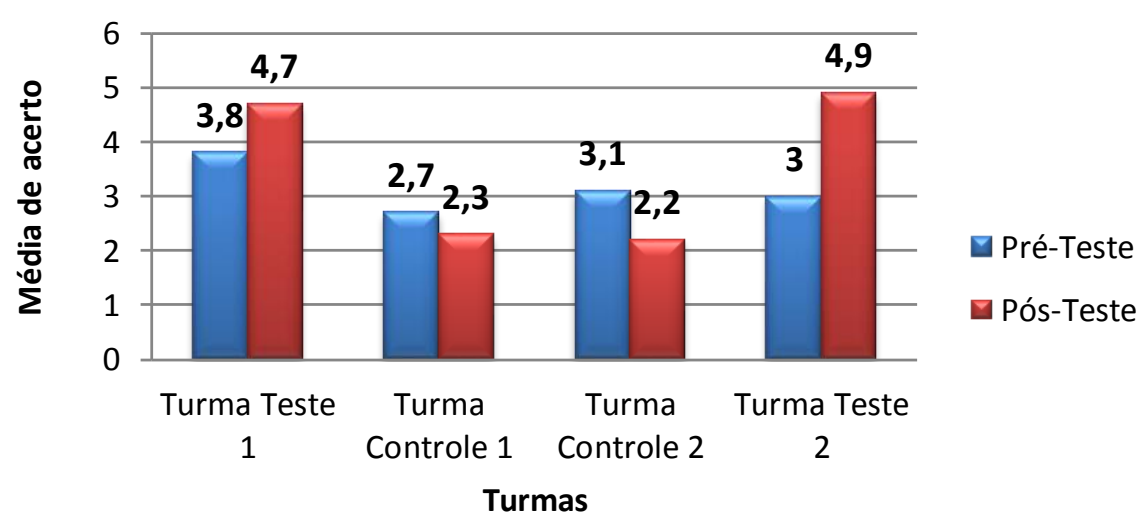

Figura 5: Médias de acertos das turmas. Fonte: Dados da pesquisa.

Além disso, é perceptível uma evolução nas médias das classificações dos resultados dos pós-teste em comparação ao pré-teste dos alunos do grupo teste, com um aumento de aproximadamente $39,5 \%$, já as turmas controle não apresentaram nenhum progresso na mesma comparação. Assim, é possível afirmar, preliminarmente, que a estratégia de utilização do jogo produziu efeitos positivos nos alunos do grupo teste, em relação aos alunos do grupo controle, verificando-se que o jogo digital pode ser utilizado como recurso instrucional e que promove um aumento dos conhecimentos adquiridos.

Os percentuais de acertos dos entrevistados, de acordo com o gênero, no questionário de pré-teste estão representados na Figura 6. É perceptível que as meninas apresentaram desempenho superior, em comparação ao desempenho dos meninos, em todas as questões do questionário de pré-teste, exceto na primeira questão, pois, na mesma os meninos tiveram um percentual de acertos maior. Considerando que os alunos foram a todo o tempo observados na aplicação dos questionários, essa diferença no desempenho pode estar relacionada ao fato das meninas estarem mais concentradas ao serem submetidas à atividade.

Em consonância com isso, percebe-se que os entrevistados, de ambos os gêneros, encontraram maior dificuldade para responder a terceira questão do questionário, porque, apenas 50\% dos meninos e $60 \%$ das meninas responderam corretamente à alternativa. Ademais, notou-se que os entrevistados encontraram maior facilidade para responder a primeira questão do questionário, pois $82 \%$ dos meninos e $78 \%$ das meninas responderam corretamente à alternativa. Há de se notar que a questão 1 do pré-teste está mais relacionada com o cotidiano dos alunos (já que se refere ao sal de cozinha), enquanto que a questão 3 pode ser considerada "decoreba", exigindo o uso da memória do aluno. 


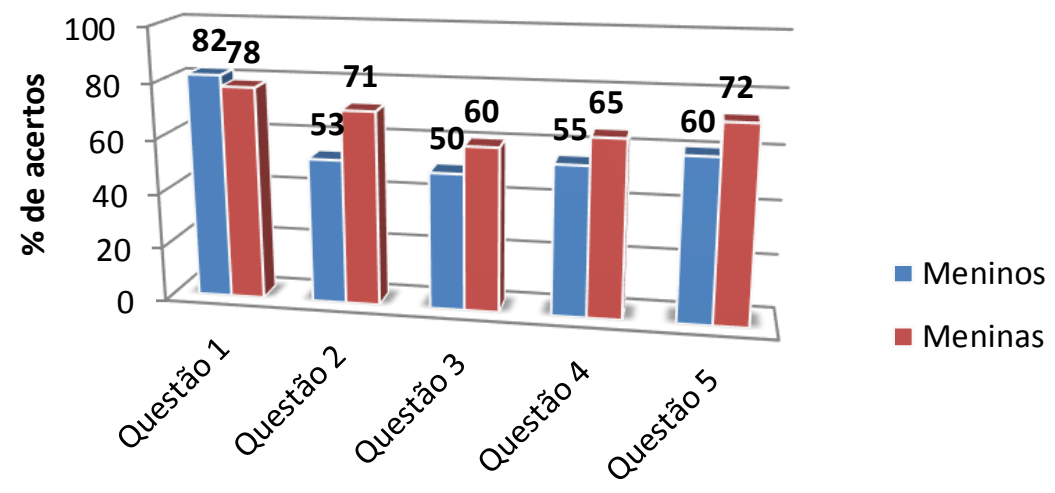

\section{Questões do Pré-teste}

Figura 6: Desempenho dos entrevistados, de acordo com o gênero, no questionário de pré-teste. Fonte: Dados da pesquisa.

Analisando os percentuais de acertos dos entrevistados, de acordo com gênero, no questionário de pós-teste, que estão representados na Figura 7 , verificou-se que as meninas apresentaram desempenho superior, em comparação ao desempenho dos meninos, na maioria das questões do questionário de pós- teste. Novamente com a observação (realizada em todas as etapas, desde o pré até o pós-testes) é possível afirmar que as meninas ficaram mais concentradas ao jogarem o QUIMIF e também ao responderem as questões.

Percebe-se que os entrevistados, de ambos os gêneros, encontraram maior dificuldade para responder a segunda questão do questionário, porque, apenas 55\% dos meninos e $69 \%$ das meninas responderam corretamente à alternativa. Como essa questão relacionada aos fertilizantes não é do cotidiano dos alunos e nem foi tratada no jogo pode-se tecer argumentos sobre essa dificuldade.

Ademais, notou-se que os entrevistados encontraram maior facilidade para responder a primeira questão do pós-teste, já que o elemento boro foi abordado na missão do jogo referente a família 3 A fazendo relação com a sua presença em fogos de artifício, porque $74 \%$ dos meninos e $76 \%$ das meninas responderam corretamente à alternativa. Há ainda que se considerar que os alunos tiveram aula expositiva acerca do assunto e as professoras de Química da instituição abordaram o uso de fogos de artifício antes mesmo do uso do QUIMIF, corroborando com o maior número de acertos nessa questão.

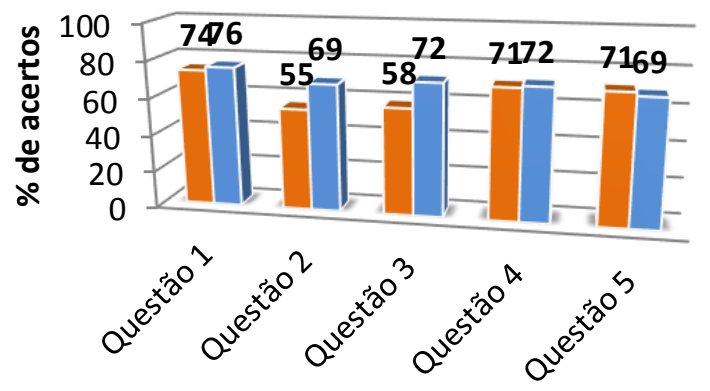

$$
\begin{aligned}
& \text { Meninos } \\
& \text { Meninas }
\end{aligned}
$$

\section{Questões do Pós-teste}

Figura 7: Desempenho dos entrevistados, de acordo com o gênero, no questionário de pós-teste. Fonte: Dados da pesquisa. 
Durante o processo de desenvolvimento dos questionários algumas similaridades entre as questões foram detectadas e o desempenho das turmas foram comparados e separados em casos. Cada caso apresenta duas questões similares, um do pré e outra do pós, e a quantidade de acertos em cada alternativa. No Caso 1, como mostra a Tabela 3, foi apresentada a primeira questão do pré-teste que aborda o assunto de maneira semelhante à segunda questão do pósteste, ou seja, as duas questões ( 1 e 2) tentam abordar aplicações dos elementos químicos.

Analisando esse primeiro caso, pode-se perceber que nas turmas testes um maior número de entrevistados acertou a pergunta que estava contida no questionário de pós-teste ( 38 acertos no pré-teste e 41 acertos no pós). Considerando as turmas testes como aquelas que foram submetidas ao jogo está claro que o uso do jogo influenciou positivamente para mais acertos no pós-teste.

Tabela 3: Primeiro caso de similaridade entre as questões do pré e pós-testes.

\begin{tabular}{|c|c|c|}
\hline \multicolumn{3}{|c|}{ Caso 1 } \\
\hline Turmas & $\begin{array}{l}\text { Questão } 1 \text { do pré-teste “Qual elemento da } \\
\text { tabela periódica está presente no sal de } \\
\text { cozinha?" }\end{array}$ & $\begin{array}{l}\text { Questão } 2 \text { do pós-teste “Qual } \\
\text { elemento da família 1A é utilizado } \\
\text { como fertilizante?” }\end{array}$ \\
\hline Turma Controle 1 & 23 acertos. & 10 acertos. \\
\hline Turma Controle 2 & 15 acertos. & 8 acertos. \\
\hline Turma Teste 1 & 22 acertos. & 19 acertos. \\
\hline Turma Teste 2 & 16 acertos. & 22 acertos. \\
\hline
\end{tabular}

Fonte: Dados da pesquisa.

Na Tabela 4, o segundo caso que apresenta a similaridade entre as alternativas 2 e 1 dos questionários de pré e pós- teste, respectivamente, demonstra que as turmas testes, também, apresentaram melhores desempenhos na questão do pós-teste (33 acertos no teste aplicado antes do uso do jogo e 46 acertos após o jogo).

Tabela 4: Segundo caso de similaridade entre as questões do pré e pós-testes.

\begin{tabular}{|c|c|c|}
\hline \multicolumn{2}{|c|}{ Caso 2 } \\
\hline Turmas & $\begin{array}{c}\text { Questão 2 do pré-teste “Em qual grupo } \\
\text { da tabela periódica está presente o } \\
\text { Oxigênio?" }\end{array}$ & $\begin{array}{c}\text { Questão 1 do pós-teste “A que } \\
\text { família pertence o Bromo? ” }\end{array}$ \\
\hline Turma Controle 1 & 13 acertos. & 10 acertos. \\
\hline Turma Controle 2 & 14 acertos. & 10 acertos. \\
\hline Turma Teste 1 & 18 acertos. & 23 acertos. \\
\hline Turma Teste 2 & 15 acertos. & 23 acertos. \\
\hline & Quantidade de acertos dos entrevistados nas questões similares por turma. \\
\hline
\end{tabular}

Fonte: Dados da pesquisa.

O terceiro caso (Tabela 5) comparou o desempenho em duas questões iguais, a quinta questão do pré-teste e a quarta do pós-teste. Os resultados não foram diferentes dos casos 
anteriores, porque, as turmas teste apresentaram resultados superiores no pós-teste, enquanto, as turmas controle apresentaram desempenho inferior.

Tabela 5: Terceiro caso de similaridade entre as questões do pré e pós-testes.

\begin{tabular}{|c|c|c|}
\hline \multicolumn{3}{|c|}{ Caso 3 } \\
\hline Turmas & $\begin{array}{c}\text { Questão 5 do pré-teste “Qual desses } \\
\text { elementos pertence à família dos Gases } \\
\text { Nobres?” }\end{array}$ & $\begin{array}{c}\text { Questão 4 do pós-teste “Qual } \\
\text { dos elementos abaixo pertence à } \\
\text { família dos gases nobres? ” }\end{array}$ \\
\hline Turma Controle 1 & 15 acertos. & 12 acertos. \\
\hline Turma Controle 2 & 16 acertos. & 11 acertos. \\
\hline Turma Teste 1 & 20 acertos. & 23 acertos. \\
\hline Turma Teste 2 & 14 acertos. \\
\hline & Quantidade de acertos dos entrevistados nas questões similares por turma. \\
\hline
\end{tabular}

Fonte: Dados da pesquisa.

No quarto e último caso que contém a similaridade entre a questão 4 e a questão 5 (Tabela 6) dos questionários de pré e pós-testes, respectivamente, notou-se que, assim como nos casos anteriores, uma maior quantidade de entrevistados das turmas testes apresentaram melhores resultados na alternativa do questionário de pós-teste.

Tabela 6: Quarto caso de similaridade entre as questões do pré e pós-testes.

\begin{tabular}{|c|c|c|}
\hline Turmas & $\begin{array}{c}\text { Questão 4 do pré-teste “Quais elementos } \\
\text { compõem o grupo dos Metais Alcalino- } \\
\text { Terrosos?” }\end{array}$ & $\begin{array}{c}\text { Questão 3 do pós-teste “Pertencem a } \\
\text { família dos calcogênios? ” }\end{array}$ \\
\hline Turma Controle 1 & $\mathbf{1 2}$ acertos. & 11 acertos. \\
\hline Turma Controle 2 & $\mathbf{1 6}$ acertos. & 11 acertos. \\
\hline Turma Teste 1 & 19 acertos. & 22 acertos. \\
\hline Turma Teste 2 & $\mathbf{1 2}$ acertos. \\
\hline & Quantidade de acertos dos entrevistados nas questões similares por turma. \\
\hline
\end{tabular}

Fonte: Dados da pesquisa.

Deste modo, analisando todos os casos é notório que as turmas testes apresentaram progressos ao concentrarem desempenhos melhores nas questões do questionário de pós- teste, desta forma, é possível afirmar, preliminarmente, que a estratégia de utilização do jogo produziu efeitos positivos nos alunos do grupo teste em relação aos alunos do grupo controle, que em maioria, não apresentou progresso nas assertivas do pós em comparação ao pré-teste, verificando-se que o jogo digital pode ser utilizado como recurso instrucional que pode promover um aumento da apreensão de conhecimentos pelo público que o utiliza.

$\mathrm{Na}$ aplicação dos questionários de pré-teste os entrevistados foram convidados a responderem uma questão subjetiva sobre as suas principais dificuldades no aprendizado da Química. Diversos aspectos foram levantados na resposta da alternativa, como mostra a Figura 8.

A maioria, 31 estudantes, apontou que possui dificuldade no entendimento da tabela periódica, assim, demonstrando a necessidade de uma ferramenta que facilite o ensino deste assunto. Outras dificuldades foram apontadas nas respostas dos entrevistados, tais como: "dificuldades em entender as fórmulas químicas"; "dificuldade para compreender os assunto da disciplina" e "dificuldades com a metodologia do professor(a)". No entanto, 15 alunos 
responderam que não possuem dificuldade com o aprendizado da disciplina e 5 entrevistados não responderam à pergunta.

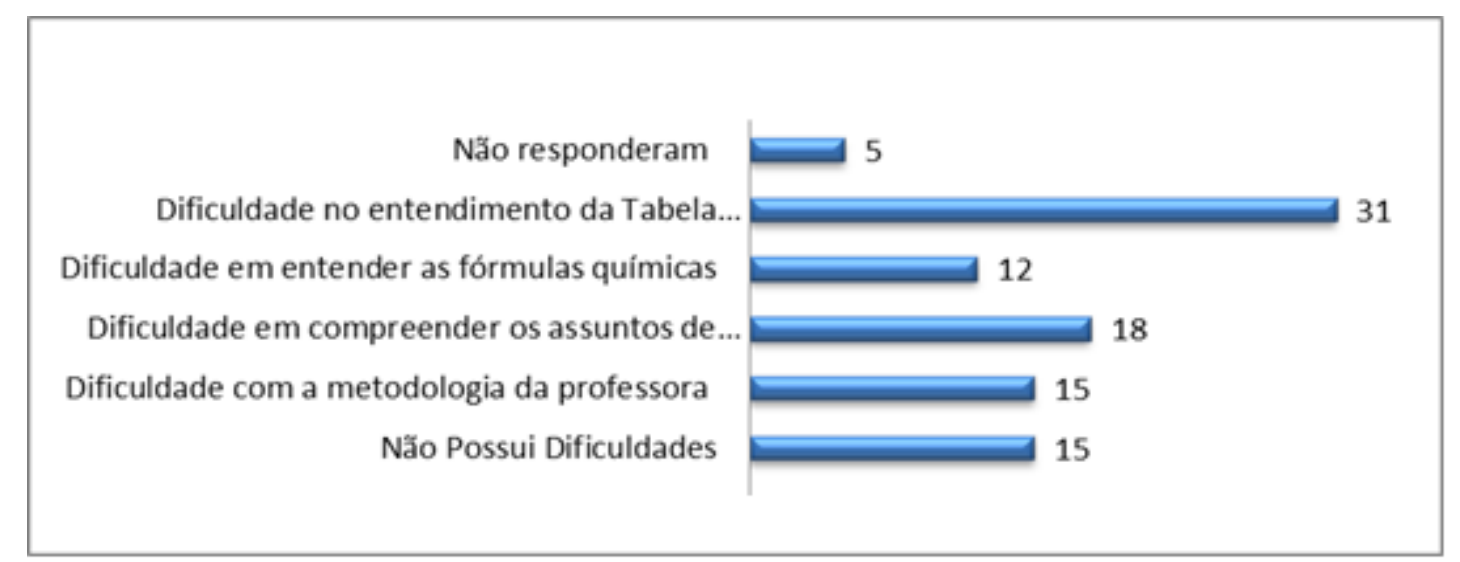

Figura 8: Principais dificuldades apontadas pelos entrevistados em química. Fonte: Dados da pesquisa.

\section{CONSIDERAÇÕES FINAIS}

Através de um jogo didático é possível facilitar o processo de ensino-aprendizagem em aulas de Química. A função educativa do jogo foi observada durante a sua aplicação. Os alunos entrevistados apresentaram uma grande aceitação à proposta apresentada e acreditamos que o jogo pode ser aceito em outros grupos escolares.

Com os resultados obtidos, pode-se afirmar que as médias das turmas teste foram superiores às turmas que não fizeram uso do jogo (controle). As turmas teste tiveram mais de $39,5 \%$ de acertos em relação às turmas controle. Além disso, pode-se afirmar que as meninas alcançaram desempenho superiores aos meninos tanto nos resultados do pré como no pós-teste. Os entrevistados apontaram que possuem muitas dificuldades para aprender o assunto tabela periódica, logo, demostrando a necessidade de uma ferramenta que facilite o ensino da temática.

Na sala de aula, os jogos proporcionam um espaço de encontro, de inclusão e de trabalho, tornando-se um bom instrumento, já que cria um significado tanto para o aluno quanto para o professor. Portanto, o jogo coopera com o desenvolvimento do aluno, pois trabalha sua capacidade de imaginar, de planejar, de criar situações adversas, de atuar, de encontrar soluções, de construir, de interagir, de criar regras, de aceitar normas e até de se auto avaliar. Por isso, o jogo se constitui como um bom recurso didático- pedagógico, e quando bem aplicado, pode se tornar uma ferramenta a mais e muito útil no processo educacional.

Desta forma acredita-se que trabalhando com o conceito de maneira lúdica e digital, a aprendizagem pode ser mais bem aceita, ao apresentar uma ferramenta nova que possa ser utilizada de forma diferente no cotidiano escolar.

\section{REFERÊNCIAS}

ARGENTO, H. Teoria construtivista. 2008. Disponível em: <http://www.robertexto.com/archivo5/teoria_construtivista.htm/>. Acesso em: o5 Jul. 2016.

CARDOSO, A. M. Desenvolvimento de um objeto de aprendizagem para o ensino da tabela periódica. 2014. Disponível em: 
<http://repositorio.ufla.br/bitstream/1/4425/1/DISSERTAÇÃO_Desenvolvimento de um objeto de aprendizagem para o ensino da tabela periódica.pdf>. Acesso em o7 ago. 2017.

FROSI, F. O.; SCHLEMMER, E. Jogos Digitais no Contexto Escolar: desafios e possibilidades para a Prática Docente. 2010. Disponível em: <www.sbgames.org/papers/sbgamesio/culture/full/fulli3.pdf>. Acesso em: 17 maio 2016.

GODOI, T. A. F.; OLIVEIRA, H. P. M.; CODOGNOTO, L.; Tabela Periódica - Um Super Trunfo para alunos do ensino fundamental e médio. Química Nova na Escola, v. 32, n. 1, p. 22-25, 2010.

HUIZINGA, J. Homo ludens: o jogo como elemento da cultura. 4. ed. São Paulo: Perspectiva, 2000.

KISHIMOTO, T. M. O jogo e a educação infantil. São Paulo: Pioneira, 1994.

OLIVEIRA, L. M. S.; SILVA, O. G.; FERREIRA, U. V. S. Desenvolvendo jogos didáticos para o ensino de química. HOLOS, ano 26, v. 5, p. 166-157, 2010.

NUNES, A. S.; ADORNI, D. S. O ensino de química nas escolas da rede pública de ensino fundamental e médio do município de Itapetinga-BA: O olhar dos alunos. In: Encontro Dialógico Transdisciplinar Enditrans, 2010, Vitória da Conquista, BA, 2010.

SOARES, M. H. F. B. Jogos e atividades lúdicas no ensino de Química: Uma discussão teórica necessária para novos avanços. REDEQUIM, v. 2, n 2, p. 5-13, 2016

WOLFF, G. Jogos digitais para a alfabetização na educação infantil. 2013. Disponível em: $<$ http://www.partes.com.br/2013/11/o1/jogos-digitais-para-a-alfabetizacao-na-educacaoinfantil/\#.V59dn6JcDjW>. Acesso em: or ago. 2017.

Adriana Vieira dos Santos: Possui graduação em Licenciatura em Química pela Universidade do Estado da Bahia (2006) e mestrado em Química Aplicada pela Universidade do Estado da Bahia (2009). Atualmente é professora de Química com dedicação exclusiva no Instituto Federal de Educação, Ciência e Tecnologia da Bahia. Também é administradora e criadora de conteúdo na página científica Vamos Falar de Ciência? e colunista na página Mundo da Química. Tem experiência na área de Química, atuando principalmente nos seguintes temas: química, educação, moodle e educação à distância, jogos no ensino de Química e preparo de soluções.

E-mail: adrianavieira@ifba.edu.br

Felipe Barbosa Araújo: Graduando no Bacharelado Interdisciplinar de Saúde na Universidade Federal da Bahia (UFBA) - Salvador - BA, iniciou sua carreira científica durante sua passagem pelo curso técnico em informática do Instituto Federal de Educação, Ciência e Tecnologia da Bahia - campus Santo Amaro, e teve trabalhos aprovados em eventos nacionalmente importantes na área da química e de informática, à exemplo, da Sociedade Brasileira de Progresso da Ciência (SBPC). É válido pontuar que suas publicações de trabalhos lhe renderam uma premiação, primeira colocação, em um evento de relevância regional, na Feira dos Municípios e Mostra de Iniciação Cientifica da Bahia (FEMMIC).

E-mail:araujolipe13@gmail.com 